\title{
ADAPTAÇÃO CULTURAL DO DIABETIC FOOT ULCER SCALE -SHORT FORM (DFS-SF) PARA A LÍNGUA PORTUGUESA DO BRASIL
}

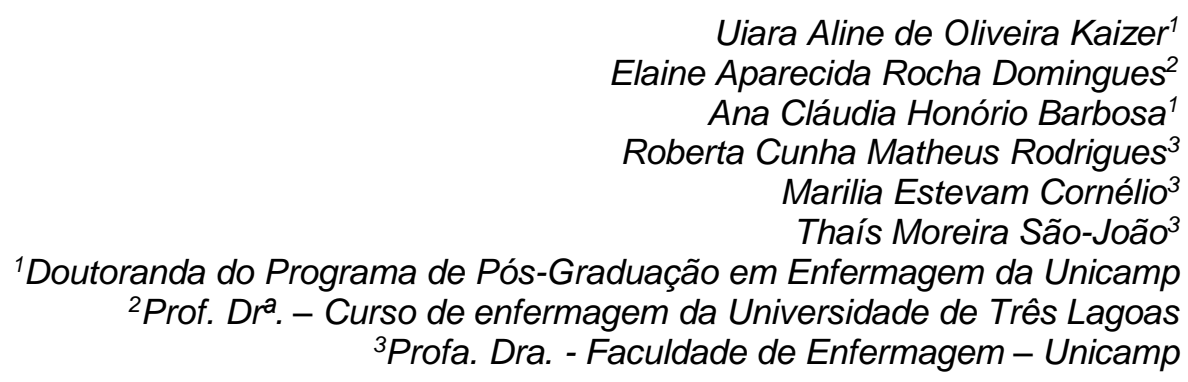

INTRODUÇÃO: A ulceração nas extremidades é a complicação mais frequente em pessoas com diabetes mellitus (DM) e representa um grave problema de saúde. Há evidências de que a qualidade de vida relacionada à saúde (QVRS), por sua vez, se agrava conforme os pacientes apresentam maiores complicações nos pés. A QVRS desses pacientes pode ser avaliada por meio de instrumentos de medida, os quais são escassos na população brasileira. OBJETIVO: disponibilizar a versão brasileira do instrumento Diabetic foot ulcer scale- short form (DFS-SF), um instrumento que avalia a QV de pessoas com pé diabético e avaliar a sua validade de conteúdo. MÉTODO: estudo metodológico, composto pelas etapas: 1) validação linguística: composta por tradução, retrotradução, avaliação pelo comitê de especialistas e pré-testagem junto aos pacientes-alvos; e 2) avaliação da validade de conteúdo, praticabilidade e aceitabilidade. $O$ estudo foi realizado em um Ambulatório de Pé Diabético do interior do estado de São Paulo. Foi utilizado um instrumento previamente testado de caracterização sociodemográfica e a versão brasileira do DFS-SF. O estudo foi aprovado sob o CAAE ํㅜ 66816717.1.0000.5404 RESULTADOS: a amostra $(\mathrm{n}=30)$ foi composta por homens $(76,7 \%)$, com 57,4 anos, brancos (86,7\%); a maioria (56,7\%) possuía mais de oito anos de estudo e era aposentada (56,7\%). A maior parte $(53,3 \%)$ apresentava diagnóstico de DM há mais de 19 anos; Classificação de Wagner 2 (46,7\%); úlcera neuropática $(76,7 \%)$ e relataram ter úlcera no pé por mais de 3 meses $(73,3 \%)$. As equivalências semântica, idiomática, cultural e conceitual entre a versão traduzida e a versão original foram obtidas. O DFS-SF foi bem aceito e de fácil 
entendimento. CONSIDERAÇÕES FINAIS: A versão brasileira do DFS-SF parece ser compreensível e de fácil aplicação. Outros estudos estão sendo desenvolvidos para avaliar sua estrutura fatorial, confiabilidade e validade interna e permitir sua utilização na prática clínica.

Palavras-chave: Diabetes mellitus. Questionários. Qualidade de vida. 